\title{
Concomitant idiopathic hypertrophic spinal pachymeningitis and Guillain-Barré syndrome in a patient: coincidence or a triggering mechanism?
}

\author{
Farouk Olubajo, MRCS, ${ }^{1}$ Tatyana Yermakova, MD, ${ }^{2}$ J. Robin Highley, DPhil, FRCPath, ${ }^{3}$ and \\ Vasileios Arzoglou, MBBS ${ }^{1}$
}

\begin{abstract}
1Department of Neurosurgery, ${ }^{2}$ Department of Neurophysiology, and ${ }^{3}$ Department of Pathology, Hull and East Yorkshire Hospitals, Hull Royal Infirmary, Yorkshire, United Kingdom
\end{abstract}

\begin{abstract}
Idiopathic hypertrophic spinal pachymeningitis (IHSP), a rare diffuse inflammatory thickening of the dura mater, and Guillain-Barré syndrome (GBS) are known entities but they have never been reported as concomitant diagnoses. To their knowledge, the authors present the first reported case in the international literature with supportive evidence for both IHSP (based on MRI, intraoperative, and histological findings) and GBS (based on history, clinical examination, and electrophysiological findings). They review the literature on IHSP and the diagnostic criteria for GBS, with the view of identifying a possible causative connection.
\end{abstract}

https://thejns.org/doi/abs/10.3171/2017.3.SPINE161112

KEY WORDS idiopathic hypertrophic spinal pachymeningitis; Guillain-Barré syndrome; acute motor and sensory axonal neuropathy; diagnostic technique

$\mathrm{I}$ DIOPATHIC hypertrophic spinal pachymeningitis (IHSP) is characterized by diffuse inflammatory thickening of the dura mater ${ }^{27}$ and subsequent spinal cord compression, with or without vascular insufficiency of the spinal cord. ${ }^{18}$ There are various associated diseases, such as tuberculosis, ${ }^{35}$ syphillis, ${ }^{24}$ IgG4-related disease, ${ }^{5,31}$ heavy chain disease, ${ }^{38}$ Wegner's granulomatosis, ${ }^{20}$ and sarcoidosis; these etiologies must be ruled out before a diagnosis of IHSP can be made. Surgical decompression, with or without steroid administration, is the mainstay of treatment: ${ }^{27}$ surgery is also important for confirming the diagnosis.

Conversely, Guillain-Barré syndrome (GBS) is characterized by acute areflexic paralysis with albuminocytologic dissociation (elevated CSF protein level with a normal white blood cell count). ${ }^{36}$ GBS has various subtypes, including acute motor and sensory axonal neuropathy (AMSAN).$^{14}$ Diagnostic criteria stress the importance of motor weakness with absent or depressed reflexes, ${ }^{2}$ but there are other features that strongly support the diagnosis, including the progression of symptoms and the symmetric pattern of weakness. CSF studies rely on a raised CSF protein level, with 50 or fewer leukocytes $/ \mu 1,{ }^{2,9}$ whereas elec- trophysiological examination requires evidence of conduction blockage and increased distal latencies in more than one peripheral nerve. ${ }^{14}$ Treatment is with intravenous immunoglobulin (Ig) or plasma exchange. ${ }^{14,26,36}$

With such contrasting elements-particularly, the different treatment modalities - it is important to distinguish these 2 diseases. We present a case in which such a distinction was not possible, as there was evidence of both diseases.

\section{Case Report}

History and Examination

A 51-year-old right-handed female, with no significant medical history, presented with a 2-day history of worsening sensation and limb function in both legs. A diagnosis of a transient ischemic attack was made, and the patient was discharged on a regimen of aspirin therapy. She presented again with a progressing paralysis. On assessment, the patient had Medical Research Council Grade 2/5 power in her proximal legs and 3/5 distally. Examination of her arms revealed a power of $4 / 5$. She had reduced sensation to light touch and pinprick, with a sensory level at T-8.

ABBREVIATIONS AMSAN = acute motor and sensory axonal neuropathy; APTT = activated partial thromboplastin time; GBS = Guillain-Barre syndrome; IHSP = idiopathic hypertrophic spinal pachymeningitis. 
All deep tendon reflexes were absent. Rectal examination revealed normal perianal tone but with no voluntary squeeze.

Because of the suspicion of a diagnosis of GBS, a lumbar puncture (LP) was attempted. This test was unsuccessful, prompting MRI. MRI revealed a diffuse extraaxial lesion that extended from T-3 to T-8 (hypointense on both T1- and T2-weighted images) with severe anterior and posterior cord compression (Fig. 1C and D).

Blood results revealed a normal full blood count and normal urea and electrolyte levels. C-reactive protein was raised at $47 \mathrm{mg} / \mathrm{L}$ (reference range $0-5 \mathrm{mg} / \mathrm{L}$ ). A prolonged activated partial thromboplastin time (APTT) of $47.9 \mathrm{sec}-$ onds (reference range 24-28 seconds) was also noted. The differential diagnosis made was of either an extramedullary tumor or a subdural hematoma. A hematoma was suspected due to the following clinical risk factors: acute deterioration, recent administration of aspirin, raised APTT, and multiple failed attempts at a lumbar puncture.

\section{Operation}

An emergency thoracic laminectomy (T4-9) was performed ( 2 days after the onset of symptoms). Intraoperative findings revealed a very tough and thickened dura, which, once divided, was adherent to the arachnoid and pia maters (Fig. 1A and B). Complete resection was not possible due to the adherence to the spinal cord, which appeared edematous and inflamed. A $4 \times 1-\mathrm{cm}$ fragment of the thickened dura was resected, and the rest of the lesion was divided to expose the cord. There was no hematoma in the extradural or the subdural space.

\section{Pathological Findings}

Pathological examination revealed paucinuclear, com- pacted bands of collagen, consistent with thickened dura with focal areas of chronic inflammation, predominantly with lymphocytes and plasma cells (Fig. 1E). Results of immunohistochemistry for IgG and IgG4 were repeatedly negative. The histological diagnosis was of IHSP.

\section{Postoperative Course}

Immediately postoperatively, the patient's neurological status deteriorated with Grade 0/5 power on the Medical Research Council scale in both legs. Power in the upper limbs also gradually reduced to Grade $1 / 5$, with some marginal improvement after a course of intravenous Ig agents and oral dexamethasone. Tests performed postoperatively are summarized in Table 1. The patient was found to have a factor XII deficiency, which explained the raised APTT on admission, despite not conferring an increased bleeding risk. ${ }^{25}$ Neurophysiological examination confirmed a diagnosis of acute motor and sensory polyneuropathy without any evidence of demyelination. A repeat test performed 4 weeks later showed some improvement in terms of amplitude and in the recruitment of motor units, despite a persistent global reduction. The diagnosis based on the electrophysiology was of AMSAN within the spectrum of GBS.

At the 10-month follow-up, the patient's neurological status had improved, with normal upper limb function, and, despite reduced function in the lower limbs, there was some improvement, with mild weakness (Grade 4/5) in the left leg and severe weakness in the right leg (1/5).

\section{Discussion}

Idiopathic hypertrophic pachymeningitis was described by Park et al. ${ }^{24}$ as being characterized by 4 features: 1 ) un-
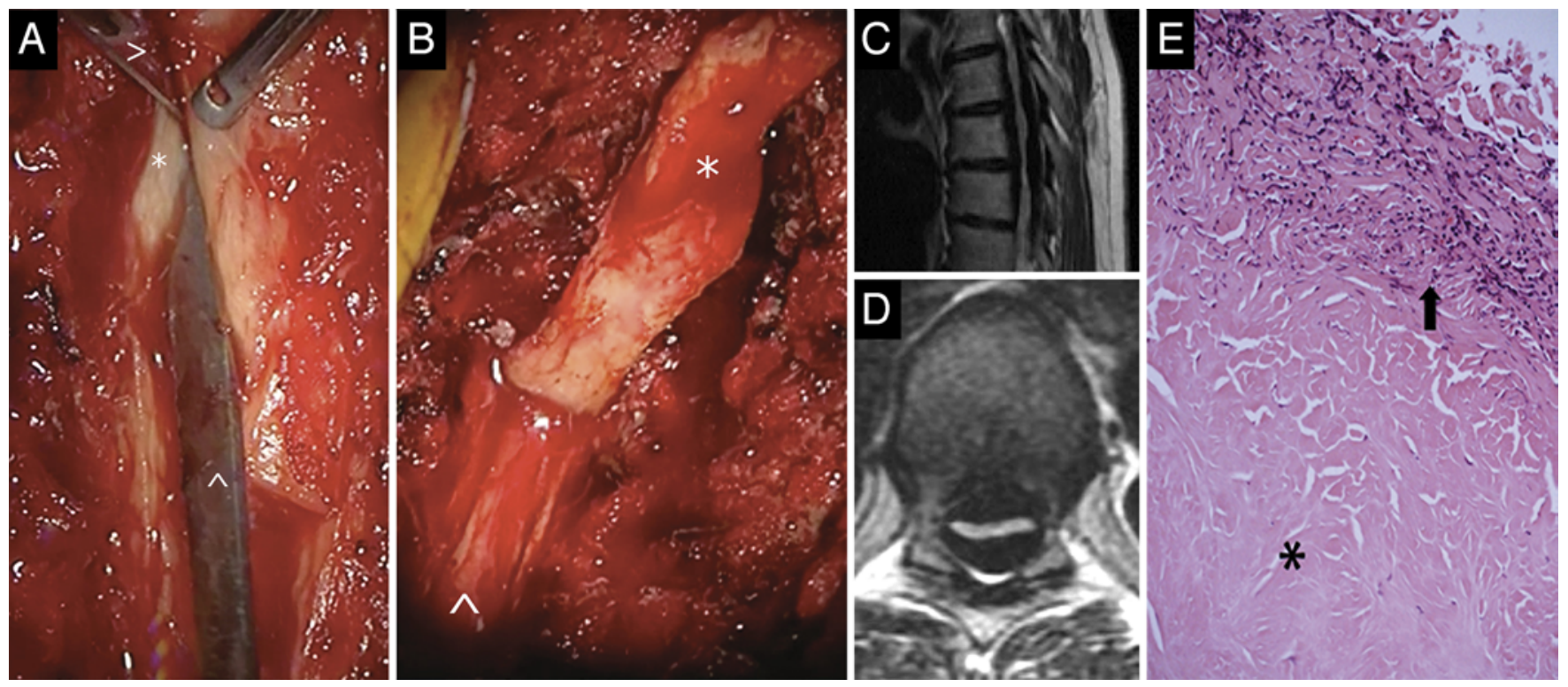

FIG. 1. Intraoperative photographs ( $\mathbf{A}$ and $\mathbf{B}$ ) showing dissection of thickened dura and exposure of underlying spinal cord as the dura is stripped off the spinal cord. ${ }^{\wedge}=$ pia/spinal cord; ${ }^{*}=$ IHSP; $>=$ scalpel. Sagittal (C) and axial (D) T2-weighted MR images showing the thoracic cord with significant cord compression (anterior and posterior) due to a uniformly hypointense lesion. Histology $(\mathrm{E})$ revealed pachymeningeal thickening with much largely anucleate collagen deposition $\left(^{*}\right)$ and a patchy chronic inflammatory infiltrate $($ arrow). $\mathrm{H} \& \mathrm{E}$, original magnification $\times 100$. 
TABLE 1. Summary of tests performed

\begin{tabular}{|c|c|}
\hline Test & Comment \\
\hline IgG subtyping & Normal lgG4 \\
\hline Serum protein electrophoresis & $\begin{array}{l}\text { Low albumin \& increasing } \\
\text { } 1 \text {-globulin; no evidence of } \\
\text { paraproteinemia; normal IgG \& } \\
\text { IgA; IgM was increased to } 3.4 \\
\text { g/L (ref range } 0.5-2.0 \mathrm{~g} / \mathrm{L} \text { ) }\end{array}$ \\
\hline Factor XII & $\begin{array}{l}\text { Factor XII deficiency (causes } \\
\text { raised APTT) }\end{array}$ \\
\hline $\begin{array}{l}\text { Serum angiotensin conversion } \\
\text { enzyme }\end{array}$ & Normal \\
\hline Beta-2 glycoprotein antibodies & Normal \\
\hline $\begin{array}{l}\text { Glomerular basement mem- } \\
\text { brane antibody }\end{array}$ & Negative \\
\hline Cardiolipin IgG & Negative \\
\hline $\begin{array}{l}\text { Antineutrophil cytoplasmic } \\
\text { antibodies }\end{array}$ & Negative \\
\hline HIV test & Negative \\
\hline Treponemal serological tests & Negative \\
\hline $\begin{array}{l}\text { CSF culture (including Mycobac- } \\
\text { terium tuberculosis) }\end{array}$ & Negative \\
\hline 9-day postop lumbar puncture & $\begin{array}{l}\text { CSF protein } 4.24 \mathrm{~g} / \mathrm{L} \text { (ref range } \\
0.10-0.40 \mathrm{~g} / \mathrm{L} \text { ) }\end{array}$ \\
\hline
\end{tabular}

Ref $=$ reference .

known etiology, 2) specific dural involvement, 3) diffuse thickening of the dura with encasement of the CNS, and 4) unique histopathology to include chronic inflammation of the dura. Isolated disease of the spine is referred to as idiopathic hypertrophic spinal pachymeningitis (IHSP) and was first described by Charcot and Joffroy in $1869 .{ }^{28}$ It is a rare cause of spinal cord compression.

Our review of the literature (Table 2) shows that the disease most commonly affects people between the 5th and 7th decades of life (age range 28-77 years; average age 50.2 years), with a female preponderance (male/female ratio 1:2). Most patients present with a degree of paraparesis, but other forms of presentation include radicular symptoms ${ }^{19}$ sensory loss, ${ }^{21}$ and neck or back pain ${ }^{4}$ with variable involvement of sphincter function. The disease commonly involves the thoracic cord and is usually circumferential, with only a few reports of disease localized to just the anterior cord. MRI features consistently reveal a diffuse hypointensity on both T1- and T2- weighted imaging, with the lesions usually enhancing with Gd administration. In the literature, all patients underwent surgical decompression either on initial presentation or on re-presentation, with a trend toward improved symptoms postoperatively. Surgery was occasionally supplemented with a course of steroids, although there is no clear consensus on the duration of the course. Other treatments include cyclophosphamide and intrathecal cytarabine, ${ }^{1}$ although these are of unproven efficacy. Early disease recurrence was reported in 8 cases (Table 2). Tsutsui et al. ${ }^{33}$ reported 5 cases of recurrence, with a follow-up of more than 10 years, stating that the course of the disease follows one of 3 patterns: 1) sustained remission, 2) relapse with corticosteroid resistance, or 3) relapse with corticosteroid dependence. Tosa et al. ${ }^{32}$ reported that a higher recurrence and poorer prognosis was seen in patients with active inflammatory signs at presentation. The mean time to recurrence is 1.3 years. ${ }^{15}$

The images and the surgical findings in our case are in keeping with those in the IHSP literature; however, the time course in our case was quicker than reported in the literature. The average duration of symptoms is 5 months, compared with our case, in which the patient progressed from dancing 7 days prior, to being quadriplegic a week later. The finding of global areflexia also rules against the diagnosis of IHSP. Of the cases in the published literature on IHSP that included information regarding reflexes, 15 patients were found to have either brisk or normal reflexes and only 2 found reduced or absent reflexes. Brisk reflexes are the expected findings in a case of compressive myelopathy; the absence of reflexes in our case is best explained by a different diagnosis. More compelling is our patient's development of severe upper-limb paresis postoperatively, despite the laminectomy being between T-4 and T-9. Any suspected deterioration in the lower limbs due to surgical manipulation would not explain deterioration in the upper limbs, as there was no exposure of the spinal cord at the origin of the brachial plexus. A thorough review of the history, clinical findings, and electrophysiological examination results demands an alternative diagnosis.

AMSAN was first described by Feasby et al. ${ }^{8}$ as a variant form of GBS. It causes a rapid decrease in the compound muscle action potential and the sensory nerve action potential without evidence of demyelination, leaving patients with an acute severe flaccid paralysis. Recovery is slow as a result of the need for regeneration of axons rather than remyelination. ${ }^{10}$ The disease is believed to follow a Campylobacter jejuni infection, ${ }^{11,37}$ which results in an IgG antibody-mediated attack on axons. ${ }^{11,12,37}$ Treatment for AMSAN is the same as that for other forms of GBS: intravenous Ig. ${ }^{36}$ Although the treatment remains the same, the prognosis is thought to be worse for patients with an axonal neuropathy. ${ }^{10,14}$

Our case has features similar to both IHSP and AMSAN, but there is more of a clinical correlation with AMSAN. The Brighton collaboration ${ }^{9}$ refined the diagnostic criteria for GBS. The highest level of diagnostic certainty requires symmetrical areflexic weakness with a monophasic illness pattern (with an interval of 12 hours to 28 days between onset and peak of illness), as well as nerve conduction findings consistent with one of the subtypes of GBS. Our patient presented with an acute onset of symmetrical areflexic weakness. Her symptoms progressed over the 48 hours prior to admission, with her symptoms peaking at Day 11. This pattern of symptom progression strongly supports a clinical diagnosis of GBS. ${ }^{2,9,29}$ In addition, electrophysiological evidence in our case repeatedly showed axonal motor and sensory involvement with no evidence of demyelination. This is consistent with AMSAN, a GBS subtype.

The Brighton collaboration ${ }^{9}$ stated that the diagnosis requires albuminocytologic dissociation (abnormally high CSF protein with a white blood cell count $<50$ cells/ $\mu \mathrm{l})$. A lumbar puncture performed 9 days postoperatively revealed a CSF protein that was markedly elevated and 


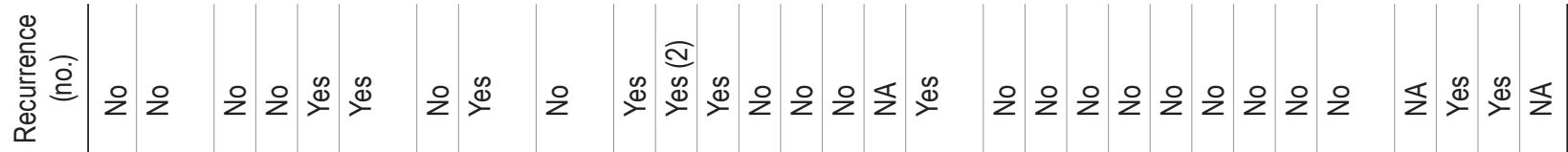

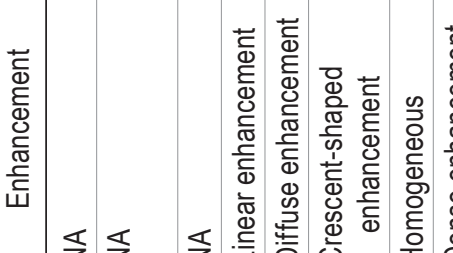

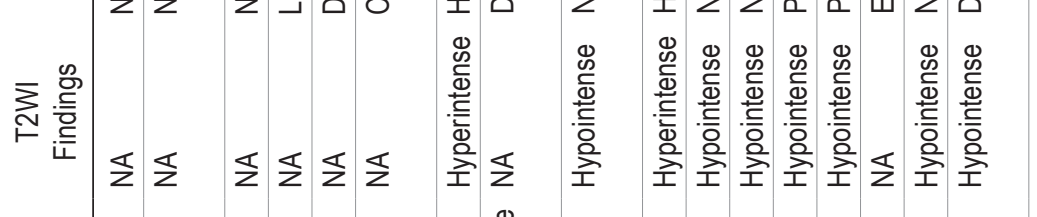

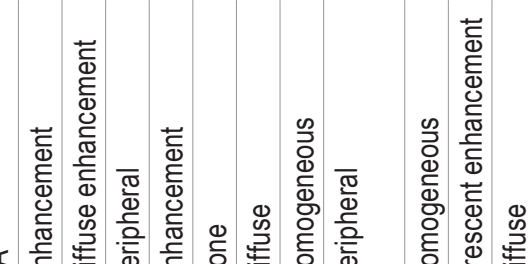

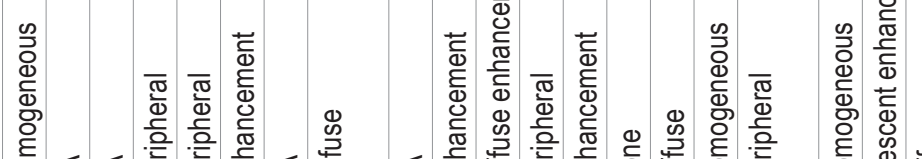

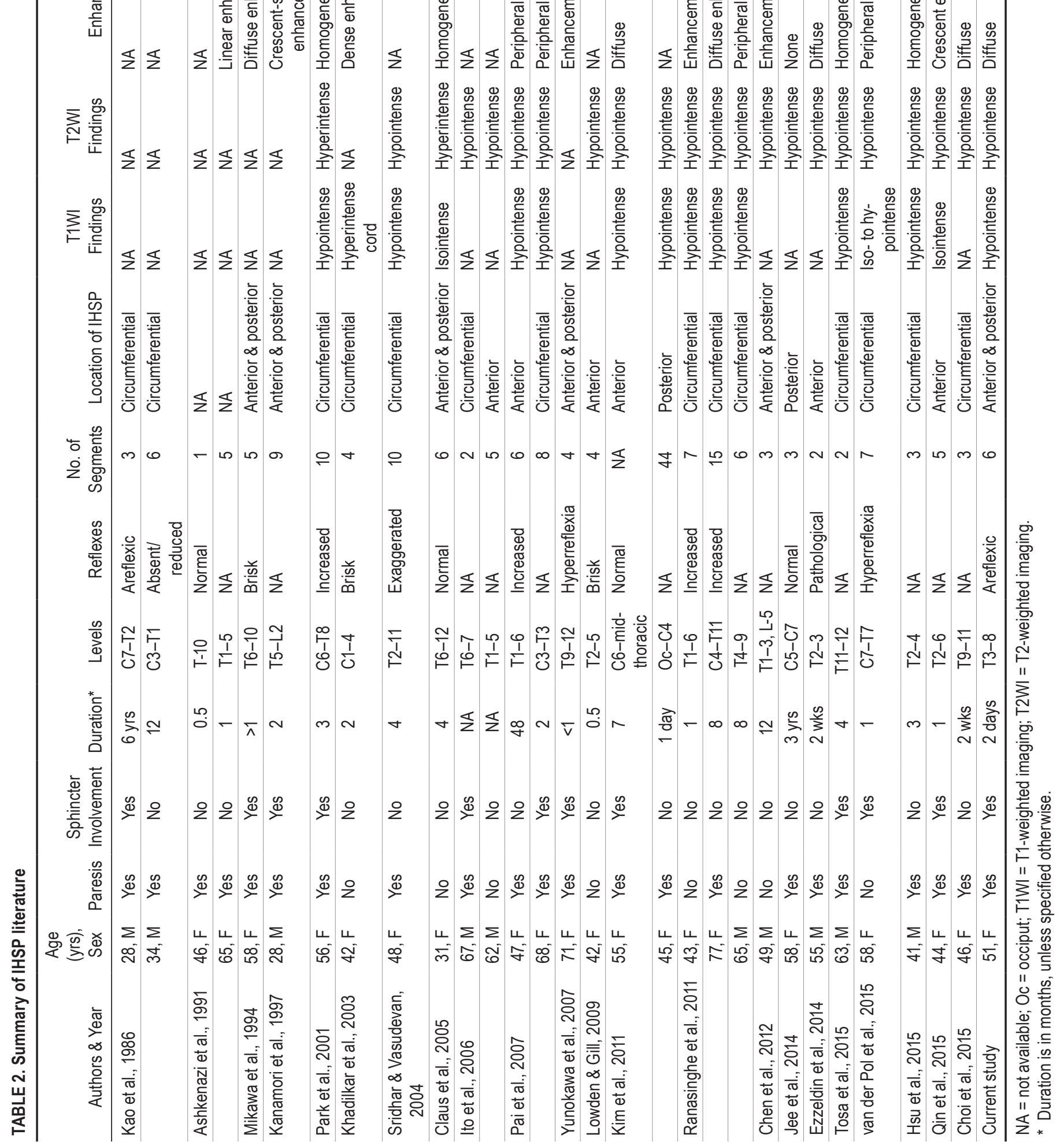


TABLE 3. Diagnostic criteria for GBS*

\begin{tabular}{|c|c|}
\hline Brighton Case Definitions & $\begin{array}{l}\text { Findings in the } \\
\text { Present Case }\end{array}$ \\
\hline Bilateral \& flaccid weakness of limbs & + \\
\hline Decreased or absent deep tendon reflexes & + \\
\hline $\begin{array}{l}\text { Monophasic course \& time btwn onset } \& \text { nadir of } \\
12 \text { hrs-28 days }\end{array}$ & + \\
\hline CSF white blood cell count $<50 / \mu l$ & $\dagger$ \\
\hline Raised CSF protein concentration & + \\
\hline $\begin{array}{l}\text { Nerve conduction findings consistent w/ one of } \\
\text { the subtypes of GBS }\end{array}$ & + \\
\hline Absence of alternative diagnosis for weakness & $\ddagger$ \\
\hline \multicolumn{2}{|c|}{$\begin{array}{l}+=\text { present. } \\
\text { * Based on the definitions in the paper by Fokke et al. With the exception of } 1 \\
\text { criterion, this patient met all criteria to ensure a Level } 1 \text { diagnostic certainty. } \\
\dagger \text { The raised CSF white blood cell count was difficult to interpret since the } \\
\text { lumbar puncture was performed } 9 \text { days postoperatively. } \\
\text { † Although there is an alternative diagnosis for weakness of the lower limbs, } \\
\text { there is no alternative diagnosis for weakness of the upper limbs. }\end{array}$} \\
\hline
\end{tabular}

a white blood cell count of 74 cells/ $\mu$. This high white blood cell count in the CSF can be attributed to the recent surgery. In fact, the patient in our case meets every criterion to ensure a Level 1 diagnostic certainty (as per the Brighton criteria), except one (Table 3). Evidence of spinal compression was listed by the group as an alternative diagnosis that precludes all levels of diagnostic certainty; indeed, our case has clear evidence of spinal cord compression, and this alone is the critical point that puts the diagnosis of AMSAN into serious doubt.

Although there is no doubt that IHSP was the result of the severe spinal compression on MRI, the history, clinical examination, and electrophysiology argue that it was not the cause of the patient's acute weakness. The improvement in upper-limb function observed at the 10-month follow-up can only be explained by a transient neuropathy that had recovered with the regeneration of axons, particularly as there was no evidence of IHSP or myelopathy in the cervical spine. However, the persistent lower-limb dysfunction is in keeping with the observed literature of surgically treated cases of IHSP, where a poorer prognosis can be seen in patients with active inflammatory signs ${ }^{32}$ such as fever, increased white blood cell count, and increased C-reactive protein levels and erythrocyte sedimentation rate at presentation, all features that existed in our case.

The concluding diagnosis/diagnoses in this case will depend on whether the clinician's reasoning follows Occam's razor or Hickam's dictum. Does the presence of cord compression immediately exclude AMSAN, and, if so, how does one explain the upper limb weakness or the areflexia? Diagnostic parsimony in this case could leave the clinician vulnerable and the patient short of a diagnosis. We hypothesize that the patient was afflicted with both diseases: AMSAN causing a loss of compensatory mechanisms with a rapid deterioration in limb function on a background of chronic IHSP. The combination of both diseases explains the persistent weakness in the lower limbs since the nerves supplying that region were afflicted with both diseases, as opposed to the upper limbs that were only affected by AMSAN.

IHSP and AMSAN may coexist, and, if present together, IHSP has the lasting effect on the patient's prognosis. Although a clear causative connection was not established in our case, when investigating an acute para-/quadriparesis one should bear in mind the very rare possibility of these 2 concomitant diseases.

\section{References}

1. Aburahma SK, Anabtawi AGM, Al Rimawi HS, Elheis MA, Mohtaseb AH: Idiopathic hypertrophic pachymeningitis in a child with hydrocephalus. Pediatr Neurol 40:457-460, 2009

2. Asbury AK, Cornblath DR: Assessment of current diagnostic criteria for Guillain-Barré syndrome. Ann Neurol 27 Suppl:S21-S24, 1990

3. Ashkenazi E, Constantini S, Pappo O, Gomori M, AverbuchHeller L, Umansky F: Hypertrophic spinal pachymeningitis: report of two cases and review of the literature. Neurosurgery 28:730-732, 1991

4. Chen H, Li Y, Mehra N, Mehra S, Fresco D, Paul JCC: Idiopathic hypertrophic pachymeningitis as a rare cause of spinal cord compression. J Med Cases 3:267-269, 2012

5. Choi SH, Lee SH, Khang SK, Jeon SR: IgG4-related sclerosing pachymeningitis causing spinal cord compression. Neurology 75:1388-1390, 2010

6. Claus E, Rutgers M, Sindic C, Raftopoulos C, Godfraind C, Duprez T: Remitting/relapsing idiopathic hypertrophic spinal pachymeningitidis: comprehensive imaging work-up and MR monitoring. Eur Radiol 15:53-58, 2005

7. Ezzeldin M, Shawagfeh A, Schnadig V, Smith RG, Fang X: Hypertrophic spinal pachymeningitis: idiopathic vs. IgG4related. J Neurol Sci 347:398-400, 2014

8. Feasby TE, Gilbert JJ, Brown WF, Bolton CF, Hahn AF, Koopman WF, et al: An acute axonal form of Guillain-Barré polyneuropathy. Brain 109:1115-1126, 1986

9. Fokke C, van den Berg B, Drenthen J, Walgaard C, van Doorn PA, Jacobs BC: Diagnosis of Guillain-Barré syndrome and validation of Brighton criteria. Brain 137:33-43, 2014

10. Griffin JW, Li CY, Ho TW, Tian M, Gao CY, Xue P, et al: Pathology of the motor-sensory axonal Guillain-Barré syndrome. Ann Neurol 39:17-28, 1996

11. Hafer-Macko C, Hsieh ST, Li CY, Ho TW, Sheikh K, Cornblath DR, et al: Acute motor axonal neuropathy: an antibodymediated attack on axolemma. Ann Neurol 40:635-644, 1996

12. Ho TW, Mishu B, Li CY, Gao CY, Cornblath DR, Griffin JW, et al: Guillain-Barré syndrome in northern China. Relationship to Campylobacter jejuni infection and anti-glycolipid antibodies. Brain 118:597-605, 1995

13. Hsu HT, Hsu SS, Chien CC, Lai PH: Teaching NeuroImages: Idiopathic hypertrophic spinal pachymeningitis mimicking epidural lymphoma. Neurology 84:e67-e68, 2015

14. Hughes RAC, Cornblath DR: Guillain-Barré syndrome. Lancet 366:1653-1666, 2005

15. Ito Z, Osawa Y, Matsuyama Y, Aoki T, Harada A, Ishiguro $\mathrm{N}$ : Recurrence of hypertrophic spinal pachymeningitis. Report of two cases and review of the literature. J Neurosurg Spine 4:509-513, 2006

16. Jee TK, Lee SH, Kim ES, Eoh W: Idiopathic hypertrophic spinal pachymeningitis with an osteolytic lesion. J Korean Neurosurg Soc 56:162-165, 2014

17. Kanamori M, Matsui H, Terahata N, Tsuji H: Hypertrophic spinal pachymeningitis. A case report. Spine (Phila Pa 1976) 22:1787-1790, 1997

18. Kao KP, Huang CI, Shan DE, Ho JT, Chang T, Chu FL: Non- 
obstructive idiopathic pachymeningitis cervicalis hypertrophica. J Neurol Neurosurg Psychiatry 49:1441-1444, 1986

19. Khadilkar SV, Menezes K, Parekh HN, Ursekar M, Bhagwati SN: Idiopathic hypertrophic cervical pachymeningitis: a case report with 5 year follow up. J Assoc Physicians India 51:391-393, 2003

20. Kim JH, Park YM, Chin DK: Idiopathic hypertrophic spinal pachymeningitis: report of two cases and review of the literature. J Korean Neurosurg Soc 50:392-395, 2011

21. Lowden MR, Gill D: Teaching NeuroImage: idiopathic hypertrophic spinal pachymeningitis. Neurology 72:e27, 2009

22. Mikawa Y, Watanabe R, Hino Y, Hirano K: Hypertrophic spinal pachymeningitis. Spine (Phila Pa 1976) 19:620-625, 1994

23. Pai S, Welsh CT, Patel S, Rumboldt Z: Idiopathic hypertrophic spinal pachymeningitis: report of two cases with typical MR imaging findings. AJNR Am J Neuroradiol 28:590 592, 2007

24. Park SH, Whang CJ, Sohn M, Oh YC, Lee CHW, Whang YJ: Idiopathic hypertrophic spinal pachymeningitis: a case report. J Korean Med Sci 16:683-688, 2001

25. Pauer HU, Burfeind P, Köstering H, Emons G, Hinney B: Factor XII deficiency is strongly associated with primary recurrent abortions. Fertil Steril 80:590-594, 2003

26. Pritchard J, Hughes RAC: Guillain-Barré syndrome. Lancet 363:2186-2188, 2004

27. Qin LX, Wang CY, Hu ZP, Zeng LW, Tan LM, Zhang HN: Idiopathic hypertrophic spinal pachymeningitis: a case report and review of literature. Eur Spine J 24 (Suppl 4):S636S643, 2015

28. Ranasinghe MG, Zalatimo O, Rizk E, Specht CS, Reiter GT, Harbaugh RE, et al: Idiopathic hypertrophic spinal pachymeningitis. J Neurosurg Spine 15:195-201, 2011

29. Sejvar JJ, Kohl KS, Gidudu J, Amato A, Bakshi N, Baxter R, et al: Guillain-Barré syndrome and Fisher syndrome: case definitions and guidelines for collection, analysis, and presentation of immunization safety data. Vaccine 29:599-612, 2011

30. Sridhar K, Vasudevan MC: Idiopathic chronic hypertrophic pachymeningitis causing thoracic cord compression. Br J Neurosurg 18:515-517, 2004

31. Tajima Y, Mito Y: Cranial neuropathy because of IgG4related pachymeningitis; intracranial and spinal mass lesions. BMJ Case Rep 2012:2012, 2012
32. Tosa M, Hara M, Morita A, Ninomiya S, Ebashi M, Kamei S, et al: Idiopathic hypertrophic spinal pachymeningitis. Intern Med 54:1923-1926, 2015

33. Tsutsui M, Yasuda T, Kanamori M, Hori T, Kimura T: Longterm outcome of idiopathic hypertrophic thoracic pachymeningitis. Eur Spine J 21 (Suppl 4):S404-S407, 2012

34. van der Pol CB, Chakraborty S, Côté I, Humphrey-Murto S, Michaud J: Case 216: hypertrophic spinal pachymeningitis. Radiology 275:303-307, 2015

35. Yamashita K, Suzuki Y, Yoshizumi H, Takahashi JB, Nogawa T: Tuberculous hypertrophic pachymeningitis involving the posterior fossa and high cervical region-case report. Neurol Med Chir (Tokyo) 34:100-103, 1994

36. Yuki N, Hartung HP: Guillain-Barré syndrome. N Engl J Med 366:2294-2304, 2012

37. Yuki N, Kuwabara S, Koga M, Hirata K: Acute motor axonal neuropathy and acute motor-sensory axonal neuropathy share a common immunological profile. J Neurol Sci 168:121-126, 1999

38. Yunokawa K, Hagiyama Y, Mochizuki Y, Tanaka N, Ochi M: Hypertrophic spinal pachymeningitis associated with heavychain disease. Case report. J Neurosurg Spine 7:459-462, 2007

\section{Disclosures}

The authors report no conflict of interest concerning the materials or methods used in this study or the findings specified in this paper.

\section{Author Contributions}

Conception and design: Olubajo, Arzoglou. Acquisition of data: Olubajo, Arzoglou. Analysis and interpretation of data: all authors. Drafting the article: all authors. Critically revising the article: all authors. Reviewed submitted version of manuscript: all authors. Approved the final version of the manuscript on behalf of all authors: Olubajo. Administrative/technical/material support: Olubajo, Arzoglou. Study supervision: Arzoglou.

\section{Correspondence}

Farouk Olubajo, Department of Neurosurgery, Hull and East Yorkshire Hospitals, Hull Royal Infirmary, Anlaby Rd., Yorkshire HU3 2JZ, United Kingdom. email: farouk@olubajo.com. 